\title{
The Essentials of Instructional Design Process in a Digital Age
}

\author{
Egbedokun, A.O. (Corresponding Author) \\ Department of Educational Technology and Library Studies,Faculty of Education, \\ Obafemi Awolowo University, Ile-Ife, Nigeria \\ E-mail: adeolaoyeegbedokun@gmail.com \\ Oteyola, T.A. \\ Department of Educational Technology and Library Studies,Faculty of Education, \\ Obafemi Awolowo University, Ile-Ife, Nigeria \\ Akinlabi, A. O. \\ Department of Educational Technology and Library Studies, Faculty of Education, \\ Obafemi Awolowo University, Ile-Ife, Nigeria \\ Adejumo, M. \\ Department of Educational Technology and Library Studies,Faculty of Education, \\ Obafemi Awolowo University, Ile-Ife, Nigeria \\ Ayodele, P. \\ Department of Educational Technology and Library Studies,Faculty of Education, \\ Obafemi Awolowo University, Ile-Ife, Nigeria
}

Received: May 11, 2017

doi:10.5296/jet.v4i2.11206
Accepted: July 6, 2017

Published: July 29, 2017

URL: http://dx.doi.org/10.5296/jet.v4i2.11206

\begin{abstract}
The thrust of this paper is to examine some important issues relating to instructional design in the digital age. The paper does not intend to discuss the details of model of instructional design but key issues such as instructional objectives specification, needs assessment, instructional strategies and media and also how learning takes place.
\end{abstract}

Keywords: Instructional design, strategies, media, delivery, prescription

\section{Introduction}

At the beginning of every school year, session and semester, teachers are mainly concerned about how to make sure every student in their class performs significantly better than what obtained in the previous session or semester. Teachers/lecturers strive to make sure that notes and media of instructional delivery are reviewed, especially with special focus on the recent trends. There are however fundamental issues that teachers do not pay keen attention to in the 
preparation of their instruction. Instructional preparation goes beyond note preparation. It is both a process and science. Brown and Green (2016) defined instructional design as a systematic development of instructional specifications using learning and instructional theory to ensure the quality of instruction. The authors further believe that instructional design is the science of creating detailed specifications for the development, implementation, evaluation, and maintenance of situations that facilitate the learning of both large and small units of subject matter at all levels of complexity. Brown and Green's description of instructional design is an attempt to point out to teachers that instructional delivery is like a surgical procedure that requires precision and accuracy in order to give room for improved performance.

Instructional design is a continuous process, undertaken not once but repeatedly. Thiagi (2008) describes instructional design as a process that never comes to an end, and that it is always a process of continuous improvement. Smith and Ragan (2005) defined the term instructional design as the systematic and reflective process of translating principles of learning and instruction into plans for instructional materials, activities, information resources, and evaluation. Reigeluth (1983) mentioned that the purpose of any design activity (activities as mentioned by Smith and Ragan) is to devise optimal means to achieve desired ends. The major job of the instructional designer is to create an event-instructional event- that will enable specific individuals to learn a skill in order to bring about change in behavior (Brown and Green, 2016). Event creation is a task that involves a lot of activities, some of which are summarized by Smith and Ragan (2005) as follows:

a. We must have a clear idea of what the learner should learn;

b. The best instruction is effective (learning takes place), efficient (least use of learners time) and appealing (motivating);

c. Students learn from many different modes;

d. Some principles of learning apply across age and content;

e. Evaluation should be done of instruction, as well as learner performance;

f. Evaluation of learners should be measured against objectives, not other people;

g. There should be congruence among objectives, activities, and assessment.

Designers' job is basically bringing these activities together using a particular instructional design model. There are a number of models (but this paper is not interested in highlighting these models) that a designer could use in guiding his job. Brown and Green (2016) opined that no matter which established model one refers to, there are generally three phases to the ID process: examination of the situation (needs, task, and learner analysis); creating instruction (planning, creating, and implementing the intervention); and evaluating the effect of the instruction. The submission of Smith and Ragan (2005); Brown and Green (2016) is that there are definitive prescribed procedures/processes that instructional designer must adhere to in order to achieve his aim.

The processes/procedures prescribed by any instructional design model identifies the essential roles that certain stages of the process plays. The roles of goals and objectives, needs assessment/analysis, instructional strategies and media and then evaluation are keys to successful delivery. This article is intended to examine the important roles these components 
of instructional design play in the instructional design process and the eventual implementation of instruction in the digital age.

\section{Instructional Goals and Objectives Specification}

It is a well-known fact that if an individual is clear about what he wants to achieve, it would be easy to navigate through any challenging times and situations to achieve. This is to underscore the fact that learning outcome or performance could only be measured using the instructional goal or instructional objective meter. Goals in the parlance of instruction/training could be referred to as the milestones that an individual can achieve. It is a way of explaining the reasoning behind what you will teach in a session, a declaration about what the teacher will. Goals are usually statements of educational intention. On the other hand, objectives are potential goals. Instructional objectives are statements that express the expected learning outcomes of the learners at the end of instruction. Morrison (2004) described a instructional objective as a statement that specifies, in behavioural (measurable) terms what a learner will be able to do as a result of instruction. It describes the intended outcome of an instruction rather than a description or summary of the content. It is but one of several steps that should be followed when developing instruction. Instructional objectives provide both you and your students with 'section direction'. Morrison further asserted that instructional objective must be learner-centred, not teacher-centred, outcomes-driven, not process-driven, objective measures, not subjective measures, specific behaviours, not vague behaviours. A well-written instructional objective should therefore meet the following criteria: (1) describe a learning outcome, (2) be student oriented, (3) be observable (or describe an observable product). Let it be mentioned clearly here that a successful instructional design process must identify the specific instructional goals and objectives to be achieved at the end of the instructional event.

In the specification of instructional objectives, the 'ultimate' goal must be thoroughly interrogated and broken down into learnable chunks. Instructional objectives are specified in such manners that will identify specifically what learners would be able to do at the end of the instruction. These specifications must also identify the sequence learners would follow in order to be able to succeed. Instructional designers must be apt to further break a particular instructional objective in smaller units of enabling objectives and essential prerequisites. While enabling objectives are the essential actions that learners must perform, essential prerequisites form the bases for supportive actions and experiences.

\subsection{Needs Assessment/Analysis}

The starting point in any teaching program is to determine whether teaching is needed and, if needed, to specify what that teaching should accomplish. So making analysis of the learners' needs is of vital importance to the success of teaching (Zheng, 2010). Instructional designers have the responsibility of determining this fact before prescriptions are made. Needs assessment is carried out to determine the gap between what is known and what should be known. This is why the goals of an instruction must have been stated and clearly considered. The term 'Needs Assessment' is often used interchangeably with 'Needs Analysis'. Needs assessment comprise of two important words: needs and assessment. 'Need' is an essential starting place for needs assessments. Though the word need is used casually in many contexts without a definition. A need has been described as: 


\section{Mll Macrothink}

- "A gap between real and ideal that is both acknowledged by community values and potentially amenable to change." (Reviere, Berkowitz, Carter and Gergusan, 1996).

- Different from such related concepts as wants ("something people are willing to pay for") or demands ("something people are willing to march for"). (McKillip, 1987)

- A gap between "what is" and "what should be." (Witkin and Altschuld, 1995)

\subsection{Approaches to the Definition of Needs}

The first approach identified by Stufflebeam is the discrepancy view, which is best characterized by the work of Kaufman (1972). It is probably the most popular approach to needs assessment. In this view, a need is a discrepancy or gap between measures or perceptions of desired performance and observed or actual performance, and herein lies a major potential problem. It is often applied in situations where norms and standards are readily available and where measurable criteria are emphasized. A second approach identified by Stufflebeam is the democratic view, which is derived from the practice than from the theory of needs to involve many people in the needs assessment process and, therefore, has high public relations value. It can be applied quite easily and can be used to sample opinion regarding a wide range of variables and potential needs. The third approach identified by Stufflebeam is the analytic view, in which a need is described as the direction in which improvement can be predicted to occur, given information about current status. It is future-oriented and involves critical thinking about trends and problems that may arise. The fourth approach, the diagnostic view, need is defined as something whose absence or deficiency proves harm or whose presence is beneficial. This approach uses logic and available research to identify and describe deficiencies that may be harmful, and requires that a relationship between two variables be documented to be able to substantiate that harm or benefit results on one variable from the withholding or provision of the other variable.

\subsection{The Needs Assessment Process}

The needs assessment process consists of five interrelated sets of activities:

1) Preparing to do a 'needs assessment'

2) Gathering desired needs assessment information

3) Analyzing the needs assessment information

4) Reporting needs assessment information

5) Using and applying needs assessment information

These steps do not necessarily occur in a strict sequence since steps can be pursued simultaneously and because recycling will inevitably (and should) occur.

The objectives of the instruction will dictate how needs assessment is to be designed and conducted. Needs assessment can either document the current situation for a group or for a target population. A needs assessment is often conducted for a specific group, organization, or business in order to improve effectiveness or productivity of the group related to its mission. Assessment objectives relates to the objectives of the organization. For a company, organization assessments learn how to close a training or performance gap (Gupta et al., 2007). 


\subsection{Importance of Needs Assessment}

Educators must deal with students, communities, and social institutions that are dynamic, resulting in changing needs. It is in the context of attempting to be responsive to these changes, and to the many wishes and needs that schools are asked to address, that needs assessment can be useful. Needs assessment is a process that helps one to identify and examine both values and information. It provides direction for making decisions about programs and resources. It can include such relatively objective procedures as the statistical description and analysis of standardized test data and such subjective procedures as public testimony and values clarification activities. Needs assessments are used to address most areas of educational programming and student growth (such as academic, emotional, social, vocational aesthetic, physical, and moral) (Stufflebeam, 1977) at local, state, regional, and national levels. Needs assessments are implemented for several reasons; two primary reasons are to assist in planning and to promote effective public relations. Other purposes include identifying and diagnosing problems and assisting in the evaluation of the merit and worth of a program or other endeavor. Thus, it is a process that can be used for many different purposes.

\subsection{Identifying Instructional Strategy}

Once the goals of the instruction have been established and the needs assessed, a plan must be enacted to transmit the knowledge, skills and attitudes to the learners. The plan may include several layers to ensure that learning takes place. This plan for management and facilitation of learning is summarily accomplished by prescribing one or a combination of instructional strategies. Instructional strategy, otherwise known as "teaching strategies" refers to the structure, system, methods, techniques, procedures and processes that a teacher uses during instruction. Instructional strategies are means through which instruction is implemented. It is therefore a must that the prescribed instructional strategy must be consistent with the content of the instruction, and must be handled/implemented appropriately. Instructional strategies refer to methods used to help students learn the desired course contents and be able to develop achievable goals. Reigeluth (1983) identified three aspects of instructional strategies: (i) organizational strategy, (ii) delivery strategy, and (iii) management strategy. These three strategies are prescribed to identify and solve different instructional problems. Organizational strategies according to Smith and Ragan (2005) refer to how instruction will be sequenced, what particular content will be presented, and how this content will be presented, delivery strategies deal with what instructional medium will be used and how learners will be grouped, while management strategies include the scheduling and allocation of resources to implement the instruction that is organized and delivered as planned within the previous two strategy aspects. The three strategies could be referred to as the characteristics of instructional strategy, which is embedded during every instructional delivery process.

Effective instruction/lesson are usually hinged on prescription and use of an array of teaching strategies, this is because there is no single, universal approach that suits all situations. Since instructional strategies are the activities of a learning process, Chellman (2011) advocates that such activities "must match learning objectives, and that to the extent possible, and appropriate, activities can and should mirror the actual expected behaviour". Some strategies however, are better suited to teaching certain skills and fields of knowledge than are others. 


\section{Mll Macrothink}

Some strategies are better suited to certain learner backgrounds, learning styles and abilities. For instance, a lecture, is the oral presentation of information by the instructor, often used in the university, as the main method of teaching. McKeachie and Svinicki (2006) believe that lecturing is best used for (i) providing up-to-date material that can't be found in one source; (ii) summarizing material found in a variety of sources; (iii) adapting material to the interests of a particular group; (iv) initially helping students discover key concepts, principles or ideas; and (v) modelling expert thinking. So, instructional designers consider the factors of age, class and content to prescribe the strategy. Despite the popularity of lectures, the lack of active involvement of trainees or learners limits its usefulness as a method of instruction. The lecture method of instruction is usually prescribed for trainees with very little knowledge or limited background knowledge on the topic.

Furthermore, discussion strategy is a more active learning experience for the trainees and learners than the lecture. A discussion is needed for learners to share experiences, ideas and attitudes. As it helps to foster trainees' involvement in what they are learning, it may contribute to desired attitudinal changes. Discussion may be used in the classroom for the purpose of lesson development, making trainees apply what they have learnt or to monitor trainees learning by way of feedback. Discussion is usually prescribed for classes such as History, Government, Literature amongst others. Demonstration Method is any planned performance of an occupation skill, scientific principle or experiment. "The most effective way to teach an occupational skill is to demonstrate it... one of the two most essential teaching skills is the ability to demonstrate; the other is the ability to explain. Both are vital to the success of either an operation lesson or an information lesson". Brainstorming method encourages ideas to flow freely, building on and improving from previous ideas. No idea, however crazy, should be rejected. These ideas are listed exactly as they are expressed on a board or flipchart, or written on bits of paper. The combination of swiftly generated ideas usually leads to a very animated and energising session. Even the more reserved participants should feel bold enough to contribute. The purpose of listing responses is to collect existing experiences and thoughts. It is usually aimed at discovering new ideas and responses very quickly. It is particularly a good way of getting bright ideas. It differs from the buzz groups' discussion in that the focus is on generating as many ideas as possible without judging them. In this technique, all ideas are given equal credence. Role play method is an instructional strategy that allows participants to use their own experiences to play a real life situation. When done well, role plays increase the participant's self-confidence, give them the opportunity to understand or even feel empathy for other people's viewpoints or roles, and usually end with practical answers, solutions or guidelines. Role plays are useful for exploring and improving interviewing techniques and examining the complexities and potential conflicts of group meetings. They help participants to consolidate different lessons in one setting and are good energizers.

\subsection{Instructional Media}

An instructional medium is defined as the physical means by which the instructional message is communicated, such as television, print materials, teacher, or computer (Smith and Ragan 1999). It is the channel through which information to be processed as knowledge is presented to learners. Briggs et al (1967) in Molwantwa (1997) submitted that instructional media refers to any and all physical means representing the entire set of stimulus conditions required in the 
instruction of a learner. Instructional media can be divided into two broad groups: electronic and print media. Electronic media as the name implies are gadgets that make use of electricity. They are electronic devices. They are categorized into software and hardware while the print media are basically those medium of instruction that are on paper. Instructional media determined to a greater extent the success of any classroom event. Instructional media when not adequately manage can constitute distractions and noise and therefore hamper the whole process of learning. It has been argued that tools do not really affects learning outcomes but the strategies employed in the design and utilization of the tools. Integrating media in classroom instruction therefore is something to be done after necessary and acceptable precautions had been taken.

Introducing media to classroom instructions should not be the goal and objectives of its application. The need to identify the appropriate channels of communication that will provide optimum learning gain and improve upon performances should motivate the selection and the use of the media. It is important that the need assessment be carried out on the type and the form of media to be employed in a specific classroom instruction. No instructional media is universal. Expected learning outcomes should fundamentally determine the instructional media to be employed. It is obvious that learners learn at different rates and have different learning needs. Therefore selecting appropriate instructional media for optimum learning gain is highly important. Selecting appropriate instructional media that will meet individual students learning needs may be tasking. A hearing impaired students probably will not gain in an instructional medium that is basically audio while a student with visual challenges may not benefit from text. Selecting media for individualized instruction thus needs a meticulous appraisal of some important factors. These factors include among others; subject matter and required students' performance, types of learning task (objectives), target population (location and size), learners' characteristics which include students' learning style, cognitive strategies, skills etc., teacher's attitude and skills, availability and accessibility, teaching space (facilities and lightning) (Romiszowski 1988 model) in Molwantwa (1997).

The model thus emphasized that the goal and objectives of the instruction must be identified and clearly stated. The objectives should also constitute steps to be taken to achieve the stated goals. A well stated objectives and clearly presented steps to achieve the goals will facilitate selection of the appropriate media. The target population should also be considered. The size, the location as well as the characteristics will also enhance the selection of appropriate media. The possible challenges that may be encountered accessing the selected media is also a factor to be considered. The quality of the media as well as its appropriateness should also be taken consideration of. The reliability and the readability cannot also be ignored. The attitude of the teacher also play a significant role in media selection. A good media can be rendered ineffective just because of the attitude of the teacher. The environment, available facilities, space, illumination, electrification are cogent factors in media selection. Molwanta (1997) submitted that media selection must be the last step to be taken after all the other factors have been considered. 


\section{How People Learn and Instructional Theory}

\subsection{How People Learn}

Psychologists in their quest to explain human behaviour extend investigation to how humans learn. This enables them to develop theories, strategies and models on how humans process information that leads to learning.

\subsection{What is Learning?}

Having correct and appropriate understanding of the word learning is very important and germane. For both teacher and the student to be able to achieve the goals of learning, right understanding of the concept is invaluable. A teacher with wrong interpretation and wrong definition of the word learning oftentimes will prevent the students from learning. Such a student may be able to recite or even describe a process yet may not have a clear understanding of such process. This can be brought to bear when such a student is required to apply what is described in solving real life problem. There may be an argument that the student had learn but in the true sense of it such a student had not. Braxter, Elder and Glaser (1996) argued that for a student to claim competency then such a student should be able to (i) provide coherent explanations (ii) generate plan for problem solution (iii) implement solution strategies and (iv) monitor and adjust their activities. It can thus be affirmed that learning involves the ability of the learner to clearly exhibit improved performance and changed behavior and attitude. Oftentime teachers engage in teaching without planning to make their students competent. They are satisfied with the ability of the students to recite given facts without understanding how applicable the recited fact is to identifying and solving human problem which is the whole essence of learning. Teachers may be observed to be busy doing nothing beneficial and enables total learning by the students. It is therefore pertinent that learning is carefully define so as to guide instructional designers as well as teachers on how people learn.

Defining learning has been beclouded with ambiguity (Barron, Hebets, Cleland, Fitzpatrick, Hauber and Stevens, 2015). Houwer and Moor (2013) also opined that the definition of learning cannot be restricted to observable change in behaviour that is brought about as a result of experience. It was posited that the observable change in behaviour was as a result of some intrinsic factors and effects. These factors that determined the observable change in behaviour was opined is learning. It was thus posited that learning is the determinant of the observable and measurable relative permanent change in behaviour. Lachman (1997) in Houwer and Moor (2013) typified learning as a process that underlies behaviour and that learning should not be confused with the product of the process which is the change in behaviour. Therefore learning can be said transcend the observable change in behaviour. It is the entire processes that brought about the change in the observed behaviour.

To study how people learn thus involve a systematic analysis of the entire processes i.e. both intrinsic and extrinsic that culminated together to ensure a relatively permanent change in behaviour of an individual or students as a result of experience(s) which may be personal or from environment. 


\subsection{The Three Basic Theories of Learning}

Theories of learning promulgated for the new age sprouted from the three fundamental theories that address the basics of learning among learners. These basic theories are Behaviourism, Cognitivism and Constructivism.

\subsubsection{Behaviourism}

Behaviourism basically emanated from defining learning as a change in observable behaviour. Pavlov, Thorndike and Skinner are the pioneers of behaviourism. Pavlov classical conditioning sees learning as a natural response to stimulus. It was argued that human learn as a result of response to stimulus. Skinner's operant conditioning believes that human beings do have a mind, but that it is simply more productive to study observable behavior rather than internal mental events. Skinner's view was rooted in a view that classical conditioning was far too simplistic to be a complete explanation of complex human behavior. He believed that the best way to understand behavior is to look at the causes of an action and its consequences. Skinners' argument was predicated on Thorndike (1905) Law of Effect. Reinforcement was introduced. It was argued that an event that is positively reinforced is likely to be repeated while the one that is negatively reinforced might not be repeated. Operant Conditioning deals with operants (intentional actions) that have an effect on the surrounding environment. Skinner set out to identify the processes which made certain operant behaviours more or less likely to occur. Behaviourism had been argued is limited in explaining how human learn because learning is much more than an observable change in behaviour.

\subsubsection{Cognitivism}

Learning according to cognitive theory is a change in learner's schemata. Cognitive Learning Theory implies that the different processes concerning learning can be explained by analyzing the mental processes first. It posited that with effective cognitive processes, learning is easier and new information can be stored in the memory for a long time. On the other hand, ineffective cognitive processes result to learning difficulties that can be seen anytime during the lifetime of an individual. The cognitive theorist argued that learning is an internal process and not a change in observable behaviour. The theory posited that human processes the information received rather than mere responding to stimuli. Therefore, learning is internal. They are of the opinion that learning occurs in the mind. Also that learning involves memory, thinking, reflection, abstraction, motivation and metacognition (Ally, 2008). Information processing is an integral part of learning in cognitivism. Cognitive theorist introduced the concept of schema. It postulated that sensations are received through the sense into the sensory store, stored in the short term memory for less than one second before processing and if it is not transfer to working memory will be loss. The information can be stored in the long term memory. Information at the long term memory can be recalled at any point in time when needed.

\subsubsection{Constructivism}

Constructivism as promulgated by Piaget is an advancement of cognitivist. Constructivism argued that learning takes place when learners construct meaning from past experiences. 


\section{Mll Macrothink}

Three stages of learning were identified in constructivism: they are assimilation, accommodation and equilibration. Constructivism sees learning as an active process in which learners construct meaning from their experiences and environment. Learners are actively engaged in learning processes in constructivism. Piaget identified four basic developmental stages. Thus at each of this stages human learn differently because they have different experiences and also because they construct meaning differently.

\subsection{Learning in the Digital Age.}

It could be observed that all these theories of learning are hinged on the perception and the definition of learning by the theorists. Learning can be summarized as the process through which the learner is being made competent in the skill and knowledge required for problem identification and problem solving in a particular environment. Students are believed to have learnt when they transcend from been a novice to an amateur and from been an amateur to a professional (Jonassen, McAleese, \& Duffy, 1993). The ultimate goal of learning is to produce professionals in problem identifications and problem solving. Access to information had increased considerably in the digital age. Processing the available information so as to proffer solutions to identified problem is the major challenge of students. Recalling and reciting statements of facts is a fragmentation process in learning in the digital age. Therefore the theory of learning in the digital age will involve the use of the three basic theories of learning. Thus, Resnik (2002) asserts that:

"This focus on information, however, is limiting and distorting, both for the field of education and for computers. If we want to take full advantage of new computational technologies, and if we want to help people become better thinkers and learners, we need to move beyond these information-centric views of computing and learning”.

In the digital age, access to information is not a challenge but how to organize the information to meaningful pact that will favour problem identification and problem solving. Connectivism as proposed by Siemen (2004) will be a very appropriate theory for the digital age learning. Suffice to say that none of the theories i.e. behaviourism, cognivitism or constructivism can stand alone as the theory of learning in the digital age. Community of inquiry framework which is the process of creating a deep and meaningful (collaborative-constructivist) learning experience through the development of three interdependent elements - social, cognitive and teaching presence is very relevant in designing instruction for the digital age. Learners are able to interact with themselves, with the teachers and with their environment. Through sharing of experiences, discussions, problem-solving amongst others, learners are able to analyze information and synthesis it to draw a plausible inference. They are able to process the information by breaking the statements down and building them up to make a whole meaningful conclusion. Thus constructing meaning from past experiences. Learning is about transforming information to knowledge. Creativity, problem-solving, self-regulated and self-directed learning environment should be provided for in the digital age. This is when the focus of the instructional designer is paramount. His prescription in terms of the instructional strategies and media must conform with the realities of the instructional problem to be solved during the lesson. 


\section{Conclusion}

Instructional design is an evolving enterprise. It is being influenced by the newer technologies and consequently the needs of learners who are digital natives. Instructional designers cannot therefore afford to hold tenaciously to the rigid or conventional model of instructional design without consideration for the needs of the target of the instruction vis-à-vis the available information technologies. This paper has thus highlighted the necessity of instructional strategies and media in the process of instruction design in the digital age. This does not underplay other essential parts of the instructional design process, but underscored their key role in the design of instruction. On one hand, strategies are mainly used to take care of the objectives and needs, while media are deployed/prescribed to convey the objectives and appeal to learners.

\section{References}

Barron, A. B., Hebets, E. A., Cleland, T. A., Fitzpatrick, C. L., Hauber, M. E., \& Stevens, J. R. (2015). Embracing multiple definitions of learning. Trends in neurosciences, 38(7), 405-407.

Baxter, G. P., Elder, A. D., \& Glaser, R. (1996). Knowledge-based cognition and performance assessment in the science classroom. Educational Psychologist, 31, 133-140.

Brown, A. H., \& Green, T. D. (2016). The essentials of instructional design ( $3^{\text {rd }}$ ed). New York: Routledge.

Carr-Chellman, A. A. (2011). Instructional design for teachers. Routledge: London \& New York.

Cohen, L., Manion, L., Morrison, K., \& Wyse, D. (2010). A guide to teaching practice (Revised 5th ed). New York: RoutledgeFalmer.

Gagne, R. M., Briggs, L. J., \& Wager, W. W. (1992). Principles of Instructional Design (4th ed.). Harcourt Brace College Publishers, Orlando, Florida.

Gupta, J. J., Doley, S., \& Bujarbaruah, K. M. (2007). Evaluation of forage based feeding system for rabbit production in northeastern region of India. Indian J. Anim. Nutr., 24(4), 216-218

Jonassen, D. H., McAleese, T. M. R., \& Duffy, T. M. (1993). A Manifesto for a constructivist approach to technology in higher education. In T. M. Duffy, J. Lowyck, \& D. H. Jonassen (Eds.), The design of constructivistic learning environments: Implications for instructional design and the use of technology, Heidelburg, FRG: Springer-Verlag. Retrieved from http://cad017.gcal.ac.uk/clti/papers/TMPaper11.html

Katie Weir, General capabilities of the millennium learner: implications for curriculum, pedagogy and assessment. AISSA National Curriculum Conference, August 5-6, 2010.

Kaufman, R. A. (1972). Educational System Planning. Englewood Cliffs, NJ: Prentice Hall. 
Kavita, G., Sleezer, C. M., \& Russ-Eft, D. F. (2007). A Practical Guide to Needs Assessment (2nd ed.). John Wiley and Sons, inc. San Francisco.

Lachman, S. J. (1997). Learning is a process: Toward an improved definition of learning. Journal of Psychology, 13(1), 477-480

Mager, R. E. (1975). Preparing instructional objectives. 2nd ed. Belmont, CA: Fearon. Retrieved from http://www.nwmissouri.edu/dept/peu/studentteach/mopta.htm

McCawley, P. F. (n.d.). Methods for Conducting an Educational Needs Assessment. University of Idaho Extension.

McKeachie, W., \& Svinicki, M. (2006). McKeachie's Teaching Tips: Strategies, Research and Theory for College and University Teachers Boston/New York: Houghton Mifflin.

McKillip, J. (1987). Need Analysis: Tools for the Human Service and Education. Applied Social Research Methods Series, 10. Sage Publications: Thousand Oaks, CA.

Morrison, K. (2004). The companion web resource for A Guide to Teaching Practice. USA: RoutledgeFalmer.

Raj, X. M. (2015). Methods, test, measurement and evaluationin in physical education ( $1^{\text {st }}$ ed.). Ashok Yekkaladevi.

Reigeluth, C. M. (1983). The elaboration theory of instruction. In C. M. Reigeluth (Ed.), Instructional design theories and models (pp. 335-382). Hillsdale, NJ: Erlbaum.

Resnik, M. (2002). Rethinking learning in the digital age. In G. S. Kirkman, P. K. Cornelius, J. D. Sachs, \& K. Schwab (Eds.), The Global Information Technology Report 2001-2002 Readiness for the Networked World.

Reviere, R., Berkowitz, S., Carter, C. C., \& Gergusan, C. G. (Eds.) (1996). Needs Assessment: A Creative and Practical Guide for Social Scientists. Washington, DC. Taylor and Francis.

Royse, D. D., \& Staton, M. (n.d.). What is Needs Assessment?

Smith, P. L., \& Ragan, T. J. (2005). Instructional design ( $3^{\text {rd }}$ ed). USA: John Wiley \& Sons.

Stufflebeam, D. L. (1977). Working Paper on Needs Assessment in Evaluation. Paper presented at the First Annual Educational Research Association Topical Conference on Evaluation, San Francisco, California.

Stufflebeam, D. L., McCormick, C. H., Brinkerhoff R. O., \& Nelson C. O. (1985). Conducting Educational Needs Assessments. Kluwer-Nighoff Publishing: Boston

Thiagi. (2008). Rapid Instructional Design. Learning Activities that Incorporate Different Content Sources. Thiagi Gameletter, February 2008. Retrieved 1 March 362009 from http://www.thiagi.com/pfp/IE4H/february2008.html\#RapidInstructionalDesign 


\section{Macrothink}

Wendy Conklin, M. A. (2006). Instructional Strategies for Diverse Learners, Corinne Burton, M.A Ed. Shell Education 5301 Oceanus Drive Huntington Beach, CA 92649-1030.

Witkin, B. R., \& Altschuld, J.W. (1995). Planning and Conducting Needs Assessments: A Practical Guide. Sage Publications: Thousand Oaks, CA.

Zheng, Y. (2010). On Needs Analysis and College English Teaching in China. Journal of Language Teaching and Research, 1(4), 477-479.

\section{Copyright Disclaimer}

Copyright reserved by the author(s).

This article is an open-access article distributed under the terms and conditions of the Creative Commons Attribution license (http://creativecommons.org/licenses/by/3.0/). 